TI 2012-054/1

Tinbergen Institute Discussion Paper

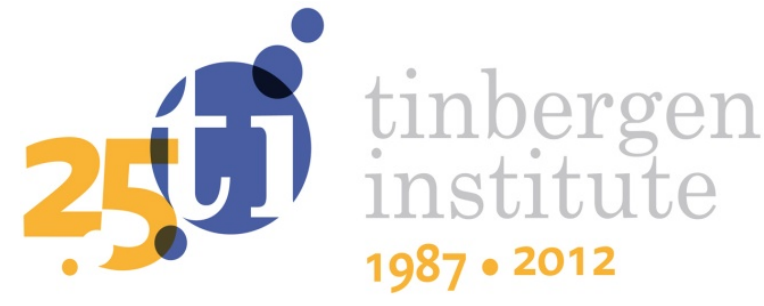

\title{
Social Relations and Relational Incentives
}

Robert Dur

Jan Tichem

Erasmus School of Economics, Erasmus University Rotterdam, and Tinbergen Institute. 
Tinbergen Institute is the graduate school and research institute in economics of Erasmus University Rotterdam, the University of Amsterdam and VU University Amsterdam.

More TI discussion papers can be downloaded at http://www.tinbergen.nl

Tinbergen Institute has two locations:

Tinbergen Institute Amsterdam

Gustav Mahlerplein 117

1082 MS Amsterdam

The Netherlands

Tel.: +31(0)205251600

Tinbergen Institute Rotterdam

Burg. Oudlaan 50

3062 PA Rotterdam

The Netherlands

Tel.: +31(0)10 4088900

Fax: $+31(0) 104089031$

Duisenberg school of finance is a collaboration of the Dutch financial sector and universities, with the ambition to support innovative research and offer top quality academic education in core areas of finance.

DSF research papers can be downloaded at: http://www.dsf.nl/

Duisenberg school of finance

Gustav Mahlerplein 117

1082 MS Amsterdam

The Netherlands

Tel.: +31(0)20 5258579 


\title{
Social Relations and Relational Incentives*
}

\author{
Robert Dur ${ }^{\dagger}$ and Jan Tichem \\ May 16, 2012
}

\begin{abstract}
This paper studies how social relationships between managers and employees affect relational incentive contracts. To this end we develop a simple dynamic principal-agent model where both players may have feelings of altruism or spite toward each other. The contract may contain two types of incentives for the agent to work hard: a bonus and a threat of dismissal. We find that good social relationships undermine the credibility of a threat of dismissal but strengthen the credibility of a bonus. Among others, these two mechanisms imply that better social relationships sometimes lead to higher bonuses, while worse social relationships may increase productivity and players' utility in equilibrium.
\end{abstract}

Keywords: Altruism, spite, social relations, incentives, relational contracts, efficiency wages, subjective performance evaluation, Nash bargaining.

JEL: D23, J33, M52, M55.

\footnotetext{
${ }^{*}$ We gratefully acknowledge comments and suggestions by Hannes Mueller, Arjan Non, Canice Prendergast, Anja Schöttner, Robin Zoutenbier, Floris Zoutman, and participants to the 2011 CESifo Area Conference on Behavioural Economics in Munich, the 2011 ZEW/Tinbergen Institute Workshop on Behavioural Personnel Economics in Mannheim, and the 2012 Workshop on the Social Dimension of Organizations in Budapest.

${ }^{\dagger}$ Erasmus University Rotterdam, Tinbergen Institute, CESifo, and IZA. E-mail: dur@ese.eur.nl.

${ }^{\ddagger}$ Erasmus University Rotterdam and Tinbergen Institute. E-mail: tichem@ese.eur.nl.
} 


\section{Introduction}

Incentive contracts for workers often do not rely on objective performance measures only. Indeed, "thinking of any job in which subjective evaluation or supervisor discretion does not play some role in incentives is difficult" (Gibbs 2012, p. 15). Subjective performance evaluation sometimes affects pay. For example, $34 \%$ of employees in the industrial sector in the UK received some form of merit pay "which depended on a subjective judgement by a supervisor or manager of the individual's performance" (quoted by MacLeod and Malcomson (1998) from Millward et al. 1992, (p. 388)). ${ }^{1}$ However, the use of subjective performance evaluation is not restricted to bonus pay only. Managers and employees regularly have an understanding that the employment relationship is only continued if performance is satisfactory, which is often a subjective matter. If the job is valuable to a worker, such a threat of dismissal also works as an incentive device (Shapiro and Stiglitz 1984). A prominent example is Henry Ford's five-dollar-day program which almost doubled wages (Raff and Summers 1987). Indirect evidence that many firms use efficiency wages as an incentive device is that bonuses are more common when the unemployment rate is low, that is, when having a job is less valuable to a worker (MacLeod and Parent 2000).

Subjective performance evaluation can overcome some well-known problems related to the use of objective performance measures, such as multitasking concerns, measurement costs, and lack of flexibility. When such problems are severe, managers may revert to 'relational contracts' in which employee performance is evaluated subjectively in a holistic way (Gibbons 1998, Prendergast 1999). However, a difficulty with relational contracts is that they cannot be enforced in court, but instead must be self-enforcing. Promises and threats contained in a relational contract may therefore be weak as they are constrained by their credibility. In recent decades, a rich theoretical literature has developed studying the optimal design and use of relational contracts (see among others Bull 1987, MacLeod and Malcomson 1989 and 1998, Baker et al. 1994, and Levin 2003).

The present paper contributes to this literature by studying how the quality of social relationships between managers and employees affects the optimal design of relational contracts. To this end we develop a simple dynamic principal-agent model where we assume that both players have some bargaining power. The relational contract may contain two types of incentives for the agent to work hard: a promise to pay a bonus for good performance as in

\footnotetext{
${ }^{1}$ See MacLeod and Parent (2000) and Gibbs et al. (2004) for similar evidence concerning subjectively determined bonuses in other sectors.
} 
Baker et al. (1994), and a high wage combined with a threat of dismissal following bad performance (efficiency wages) as in Shapiro and Stiglitz (1984). Our key innovation is that we allow both players to have feelings of altruism and/or spite toward each other. These feelings need not be symmetric. Our analysis yields several potentially testable hypotheses on how vertical social relationships in the workplace affect contract design.

So far, relational contracts have been studied abstracting from social relationships between the contracting parties. ${ }^{2}$ This is somewhat surprising given the prevalence of relational contracts in the workplace, as described above, and the abundance of evidence for the existence of social relationships between managers and employees. Surveys among managers reveal that friendships between managers and employees occur frequently (see for instance Berman et al. 2002). Furthermore, Agell (2004) reports that more than $60 \%$ of managers in Sweden use good manger-employee relationships to a great or fairly great extent for worker motivation. He concludes that managers deem social relations a superior motivator to the standard tools discussed in agency theory. Similarly, Campbell and Kamlani (1997) find that a large majority of US compensation managers deem good quality manageremployee relations more important in determining effort than good working conditions, high wages, and monitoring. ${ }^{3}$ There is also evidence for the occurrence of bad manager-employee relationships. Moerbeek and Need (2003) report Dutch data showing that in eight percent of the jobs respondents had in their lives, they got along with their manager badly or very badly. More tentatively, Kahneman et al. (2004) report diary evidence from a US sample of employed women showing that of all regular daily activities, respondents dislike most to interact with their boss. ${ }^{4}$

The results of our analysis are as follows. Our first key result is that better social relationships (meaning that either the principal, the agent, or both are more altruistic) improve the credibility of a promise to pay a bonus,

\footnotetext{
${ }^{2}$ The only exception is the recent paper by Cordero Salas and Roe (2012) that considers the case of an altruistic principal who may promise a bonus to a selfish agent. We discuss this paper in the next section.

${ }^{3}$ In line with this, an extensive literature in organizational psychology has established a strong positive correlation between the quality of the manager-employee relationship and employee performance (see Gerstner and Day 1997, Rhoades and Eisenberger 2002, and Wayne et al. 1997).

${ }^{4}$ There is also substantive laboratory evidence indicating that a majority of people are altruistic, even to strangers (see among others Andreoni et al. 2008, Andreoni and Miller 2002, Charness and Haruvy 2002, Cox 2004, Cox et al. 2007, Gneezy et al. 2000, and Leider et al. 2009). However, other people are actually spiteful. For instance, Andreoni and Miller (2002) find that $55 \%$ of their sample is altruistic while $23 \%$ is spiteful (see Beckman et al. 2002, Falk et al. 2005, and Fehr et al. 2011 for similar evidence).
} 
ceteris paribus. The reason is twofold. First, better social relationships make the relational contract more valuable, which gives the principal stronger incentives to adhere to it. Second, an altruistic principal partly internalizes the benefits of the bonus to the agent, which reduces the principal's costs of honoring the contract.

The second key result is that better social relationships undermine the credibility of a threat of dismissal. The intuition is that, as above, better social relations make the employment relationship more valuable, also if the worker shirks. As a consequence, the principal may find it attractive to retain a worker with whom she has good ties even if the worker shirks, implying that a threat of dismissal is not credible.

We find that social relationships have the following implications for optimal relational contracts. First, for very bad social relationships, players don't contract even though the economic surplus from trading is positive. This holds because bad social relationships imply a social cost from entering into an employment relationship.

Second, in the other extreme where social relationships are very good, the agent is so altruistic that no incentives are required at all to make him work hard. The reason is that an altruistic agent enjoys enriching the principal. Hence, the optimal contract is a flat-wage contract without a threat of dismissal that, nevertheless, results in high effort.

Third, for moderate social relationships both incentive types are credible. In that case, the use of both incentives is sometimes necessary to induce high effort. However, it can also happen that players are indifferent between using both incentives or only one of them. The reason is that either the principal's rents may be so large that she can promise a high bonus which alone induces high effort, or the agent's job may be so valuable to him that only a threat of dismissal provides sufficiently strong incentives, or both.

Fourth, for sufficiently good social relationships a threat of dismissal is no longer credible and so the only available incentive is a promise to pay a bonus. The optimal relational contract induces high effort through bonus pay if the discount factor is sufficiently high. If the latter condition is not satisfied, neither a threat of dismissal nor a bonus is credible, but players still enter into an employment relationship. The reason is that, if a threat of dismissal is not credible, it is by definition attractive to hire the agent even if he shirks. Hence, the optimal contract has no incentives and results in low effort.

Finally, starting from such a low-effort contract, we find two counterintuitive comparative static results. First, better social relationships can lead to higher bonuses. This follows directly from the first key result that better social relationships improve the credibility of a bonus. Second, worse social 
relationships can lead to higher effort. This holds because worse social relationships make a threat of dismissal credible, which implies that it becomes possible to contract on high effort. As a result, a marginal deterioration of a social tie can increase players' utility in equilibrium.

The paper is organized as follows. The next section briefly discusses related literature. Section 3 presents the model and section 4 contains the main analysis and results. Section 5 concludes.

\section{Related Literature}

Our model combines two strands in the literature: one on relational contracts and one on social preferences in the workplace. As for the relational contracts literature, our contribution is to study the impact of social relationships between the principal and agent on the design of relational contracts. Our paper is closely related to the seminal paper by MacLeod and Malcomson (1989) who also study relational contracts that may consist of a bonus and efficiency wages. One of their key results is that the self-enforceability of relational contracts is independent of the type of incentives used, i.e. it does not matter for the credibility of the contract whether some effort level is sustained by a bonus, efficiency wages or a combination of these two. The intuition is that any party earning rents is willing to make costs to uphold the contract. A credible bonus hence requires the principal to earn rents, whereas an efficiency wage contract must transfer rents to the agent. The only requirement is that the rents are large enough for each player to be willing to incur costs, be they payment of a bonus or cost of effort.

An implication of this result is that, if the principal has all the bargaining power, she only offers a bonus and never efficiency wages because this allows her to keep all the rents. However, if the agent has some bargaining power, as in Cordero Salas (2011), the optimal contract contains both a bonus and efficiency wages, and sometimes even only efficiency wages. The reason is that the agent always earns a rent from employment. Importantly, bargaining does not introduce other distortions and leaves the self-enforceability of relational contracts intact. This holds because bargaining merely changes the division of rents, not the size. Our assumption of bargaining hence allows a clear-cut analysis of the impact of social relationships on relational contracts that may include efficiency wages.

The effects of social relationships between principal and agent on relational incentive contracts is a topic that hardly received attention so far. To the best of our knowledge, the only existing contribution is Cordero Salas and Roe (2012) who study the case of an altruistic principal who may promise 
a bonus to a selfish agent. As in our analysis, the credibility of the bonus increases in the principal's altruism. Our paper differs in that we allow both players to have feelings of altruism and spite. Moreover, as both players have some bargaining power, the relational contract may contain efficiency wages. Also related is Brown et al. (2004) who study relational contracts in the laboratory. They formally derive, and confirm, the hypothesis that if some unobserved fraction of agents is reciprocal, long-term relational contracts will emerge that generate high effort levels, exhibit rent-sharing, and punish low effort with dismissal. The reason is that principals pay rents in order to motivate reciprocal agents which, in turn, gives selfish agents an incentive to mimic reciprocal workers (see also Brown et al. 2008). Our paper differs in that we assume that players are unconditionally altruistic or spiteful, types are observable, and we focus on one principal-agent pair. Importantly, we also allow the principal to have feelings of altruism or spite.

Much more attention has been devoted to the interaction between social preferences and incentives in static models. The theoretical literature can be divided into two groups of studies, one studying 'horizontal' social preferences and the other studying 'vertical' social preferences. The first group focuses on situations where people have social preferences towards others at the same level in the organizational hierarchy, like in co-worker relationships. ${ }^{5}$ The second group considers, as we do, social preferences towards people at a different level in the hierarchy, like manager-employee relationships.

A seminal paper in the field is Prendergast and Topel (1996)'s model of favoritism in organizations. In their principal-supervisor-agent model, the supervisor subjectively evaluates the agent's performance and reports this to the principal. The supervisor's report is the basis for the agent's remuneration. Further, the supervisor may be altruistic or spiteful towards the agent, which leads him to distort his performance reports. In a static context, Prendergast and Topel (1996) study a rich set of issues including optimal performance pay for employees, the extent of the supervisor's authority, and the use of bureaucratic rules in pay and promotion decisions (see Prendergast 2002 and Giebe and Gürtler 2012 for interesting extensions). Lee and

\footnotetext{
${ }^{5}$ Models have been developed studying the effect of envy among employees on piece rates (Bartling and Von Siemens 2010a), tournament incentives (Grund and Sliwka 2005, Bartling 2011), team incentives (Rey-Biel 2008, Bartling and Von Siemens 2010b), and relational incentives (Kragl and Schmid 2009, Kragl 2009 and 2011). Other models assume horizontal inequity aversion and derive implications for optimal piece rates (Englmaier and Wambach 2010, Neilson and Stowe 2010), tournament incentives (Itoh 2004, Ederer and Patacconi 2010), and team incentives (Itoh 2004, Englmaier and Wambach 2010). Von Siemens (2010 and 2011) study screening contracts for inequity averse workers. Lastly, Rotemberg (1994) and Dur and Sol (2010) study how incentive contracts can affect employees' willingness to invest in co-worker altruism.
} 
Persson (2011) also develop a three-layer model and allow for two-sided altruism between supervisor and agent. They show that although a supervisor's altruism induces leniency, agent's altruism induces loyalty such that social relationships in the workplace may well be in the interest of the principal. Moreover, they show that when social relationships intensify, the dominant governance mode shifts from a controlling authority regime to a trusting loyalty regime. We differ from these papers in two important ways. First, we adopt a dynamic setting which allows us to study the impact of social relations on relational incentives. Second, we focus on the case where the manager is residual claimant, implying that the credibility of incentives becomes a concern.

In different contexts, Sliwka (2007), Shchetinin (2010), and Non (2012) have studied incentive provision to altruistic employees by (possibly) altruistic managers. A common result - that we will also obtain in our analysis - is that altruistic employees require a lower bonus as they enjoy enriching the principal. Analogously, Itoh (2004), Dur and Glazer (2008), and Englmaier and Wambach (2010) study optimal incentive contracts for employees who are envious or inequity averse (that is, care about the difference between their manager's and their own payoff). ${ }^{6}$ As in our analysis of spiteful employees, such social preferences are a disincentive to provide effort. Pay-for-performance weakens this disincentive, as employee's effort enriches the manager to a smaller extent. As compared to all of these studies, our key innovation is to study pay-for-performance based on the manager's subjective evaluation, rather than on objective performance measures, in a dynamic model. Contrary to received wisdom based on static models, our dynamic model predicts that better social relationships sometimes lead to higher bonuses rather than lower, because good social relationships function as a credibility device.

\section{The Model}

We develop a principal-agent model where both players may be altruistic or spiteful toward each other. Altruism and spite are modelled as the dependence of a player's utility on another player's utility. Altruism and spite apply to someone else's total utility, possibly including an altruistic or spiteful part. This seems most natural as altruism and spite are a regard for

\footnotetext{
${ }^{6}$ See also Fehr and Schmidt (2000) and Fehr et al. (2007) who study whether a fairminded principal offers to a (potentially) fair-minded agent an explicit contract which imposes a fine for low performance, an implicit contract promising a bonus for high performance, or a trust contract consisting of a base salary only.
} 
someone's well-being and not just part thereof. ${ }^{7}$ The utility of the principal is given $b y^{8}$

$$
\Pi=\pi+\gamma U,
$$

where $\pi \equiv q(e)-w$ is the principal's profits, $w$ is the agent's compensation, and $q(e)$ is output which is a function of effort $e$. The term $\gamma U$ denotes the altruistic part of utility where $U$ is the agent's utility and $\gamma$ denotes the degree of the principal's altruism. We call $\gamma$ the principal's altruism parameter. Similarly, the agent's utility is given by

$$
U=u+\alpha \Pi,
$$

where $u \equiv w-\theta e$ is the agent's private utility, consisting of his compensation minus effort costs. The term $\alpha \Pi$ is the agent's altruistic utility, where $\alpha$ is the agent's altruism parameter. Clearly, an altruism parameter below zero reflects spite.

We assume that players know each other's altruism parameter. Further, we assume that neither player cares for the other's utility as much, or more, as he cares for his own utility; that is, $\alpha, \gamma \in(-1,1)$. The players' utility functions - which are infinite recursions of each other - can therefore be expressed $\operatorname{as}^{9}$

$$
\Pi=\frac{1}{1-\alpha \gamma}(\pi+\gamma u), \quad \text { and } \quad U=\frac{1}{1-\alpha \gamma}(u+\alpha \pi) .
$$

In each period that the agent is employed, he can exert low effort or high effort, denoted by $e \in\{0,1\}$. Low effort results in low value of output, $q=L$, while high effort yields high value of output, $q=H$. The costs of exerting high effort to the agent are $\theta$ while exerting low effort is, for reasons of convenience but without loss of generality, assumed not costly. To make the problem interesting, we assume $H-\theta>L>0$ and $H-\theta>\bar{\Pi}+\bar{U}$, where $\bar{\Pi}>$ 0 and $\bar{U}>0$ are the principal's and the agent's outside options, respectively. These assumptions imply that if players could write complete contracts, and if they are neither altruistic nor spiteful $(\alpha=\gamma=0)$, they would contract on high effort. Our assumption that $L>0$ could be interpreted as a situation where the agent performs various regular tasks such that, even though the agent would exert low effort, he would still bring value to the firm. We

\footnotetext{
${ }^{7}$ The same approach is taken by Barro (1974), Becker (1974), and Bernheim and Stark (1988).

${ }^{8}$ Unless otherwise stated, all variables are defined on a per-period basis.

${ }^{9}$ For a thorough exposition of when interdependent utility functions form a unique system and can be defined on underlying utility drivers instead of some person's utility, see Bergstrom (1999).
} 
deliberately do not put a restriction on the value of low output as compared to the outside option utilities $(L \gtreqless \bar{U}+\bar{\Pi})$. The principal's outside option $\bar{\Pi}$ reflects the value of not employing the agent; the agent's outside option $\bar{U}$ is the value of not being employed by the principal. $\bar{\Pi}$ and $\bar{U}$ are independent of player's type, which has three implications. First, the pair $(\alpha, \gamma)$ is specific to this relationship and thus does not reflect players' general altruistic or spiteful attitudes. Second, the social relationship vanishes if the players do not contract with each other (anymore). Third, $\bar{\Pi}$ and $\bar{U}$ can be interpreted as including the expected quality of social relationships that would result when being matched to some other player.

The second important ingredient of the model is that effort and output can only be assessed subjectively, and hence contracts that condition effort or output are not enforceable in court. Any contract that includes compensation or punishment that is conditional on effort or output must therefore be selfenforcing. This can only hold in a repeated interaction setting. The model therefore includes an infinite number of periods, where players discount utility from future periods by a constant common factor $\delta$. The self-enforceability of relational contracts depends further on the punishments inflicted upon the principal when she does not keep a promise or carry out a threat when the contract calls her to do so. Many models assume that the agent plays a trigger strategy that prescribes to break off trade when the principal reneges (e.g. Bull 1987, MacLeod and Malcomson 1989 and 1998, and Levin 2003). Following Baker et al. (1994), we do not impose that the agent always leaves the firm after contract breach. Instead we assume that after contract breach the agent will never believe any promise or threat in the future anymore. Note that because this is a dynamic game of complete information, we solve for the subgame perfect equilibrium of the game. ${ }^{10}$

The order of the game within a period is as follows. First, the principal chooses whether or not to hire the agent. Second, if the agent is hired, the players bargain over a contract which may contain a contractible base salary $(s)$, a promise to pay a bonus $(b)$ in case of high output, and a threat of dismissal in case of low output. ${ }^{11}$ Without loss of generality, the outcome of

\footnotetext{
${ }^{10}$ One could argue that, if the principal employs more than one agent, she could overcome a possible credibility problem by using a tournament (see Carmicheal 1983a, 1983b, Malcomson 1984, 1986, and Kragl 2011). While this may resolve the principal's problem of credibly committing to pay a bonus, multiple agents introduce a new credibility problem in the assignment of the bonus. That is, the principal will be tempted to award prizes to the agents she likes most rather than to the best-performing agents.

${ }^{11}$ Throughout the paper, we abstract from the use of severance pay (or bonds). Severance pay leaves the credibility of bonus pay unaffected (MacLead and Malcomson 1989). However, negative severance pay (that is, contracting on a transfer from the agent to
} 
contract negotiations are assumed to be given by generalized Nash bargaining, as in Cordero Salas (2011). ${ }^{12}$ Third, if a contract is agreed upon, the agent chooses an effort level. Fourth, output is realized and observed by both players. The principal decides whether or not to pay the bonus, and payoffs are realized. After that, a new period starts. By not rehiring the agent in this new period, the principal can exercise a threat of dismissal.

Typically, repeated games have many non-stationary equilibria. As is usual in the literature, we focus on stationary equilibria, that is, the principal and agent agree to the same contract every period. ${ }^{13}$ Also, we assume that the contract only contains a particular type of incentives if necessary and credible.

\section{Analysis}

In this section we solve the model described above. We start by deriving the first-best contract and analyze how it is affected by social relationships. Most of these properties will be shown to also apply to relational contracts which are derived and discussed afterwards. We finish with characterizing optimal relational contract design for any pair $(\alpha, \gamma)$.

\subsection{Complete Contracts}

In this subsection we assume players can write complete contracts which consist of an effort level $e$ and the agent's compensation $w$. Since effort is contractible, there is no need for incentives. If the principal decides to hire the agent, players enter into negotiations over the content of the contract. Generalized Nash bargaining states that the outcome of negotiations is given by the solution to

$$
\max _{e, w} \Phi \equiv[\Pi(e, w)-\bar{\Pi}]^{1-\beta_{A}}[U(e, w)-\bar{U}]^{\beta_{A}},
$$

the principal in case the principal dismisses the agent) can be used to make a threat of dismissal credible.

${ }^{12}$ For an extensive discussion on how bargaining affects relational contracts, see Cordero Salas (2011).

${ }^{13}$ By Levin (2003)'s argument, stationary contracts are optimal because they can give the agent the same incentives as any non-stationary compensation plan. This holds because in this model future rents and a bonus are perfect substitutes. Also note that the credibility of the bonus is unaffected by the choice whether to use future rents or a bonus (see the discussion of MacLeod and Malcomson (1989) in Section 2). Finally, the credibility of a threat of dismissal is independent of the issue of (non-)stationarity, as will become clear in the next section. Hence, any complex compensation plan can be replicated by a stationary one, maintaining the agent's incentives and the credibility of the contract. 
subject to the players' participation constraints

$$
\Pi(e, w)-\bar{\Pi} \geq 0 \text { and } U(e, w)-\bar{U} \geq 0 . \quad\left(\mathrm{PC}_{P}, \mathrm{PC}_{A}\right)
$$

If the players fail to reach an agreement, then they receive their outside option utilities. The agent's bargaining power is represented by $0<\beta_{A}<1$. Note that in the extreme case where $\beta_{A}=0$, the principal has the power to make the agent a take-it-or-leave-it offer. Also note that players never leave money on the table because all output that is not transferred to the agent in the form of compensation automatically accrues to the principal.

The first-order condition of $\Phi$ to $w$ yields, after some rewriting, the sharing rule:

$$
\frac{U(e, w)-\bar{U}}{\Pi(e, w)-\bar{\Pi}}=\frac{1-\alpha}{1-\gamma} \frac{\beta_{A}}{1-\beta_{A}} .
$$

Substituting $U(e, w)$ and $\Pi(e, w)$ and rewriting to $w$ yields the agent's total compensation level:

$$
\begin{aligned}
w^{*}(e)= & \frac{1}{1-\alpha}[(1-\alpha \gamma) \bar{U}+\theta e-\alpha q(e)]+ \\
& \beta_{A} \frac{1-\alpha \gamma}{(1-\alpha)(1-\gamma)}[q(e)-\theta e-(1-\gamma) \bar{U}-(1-\alpha) \bar{\Pi}],
\end{aligned}
$$

which is discussed in detail at the end of this subsection. Given that the agent's compensation equals $w^{*}(e)$, both players' participation constraints reduce to

$$
S(e) \equiv q(e)-\theta e-(1-\gamma) \bar{U}-(1-\alpha) \bar{\Pi} \geq 0, \quad\left(\mathrm{PC}_{P}, \mathrm{PC}_{A}\right)
$$

where $S(e)$ denotes the surplus from the relationship. The first-order condition (2) reveals why both players' participation constraints are identical: bargaining implies that players divide the surplus of the relationship proportional to players' bargaining power. Hence, all that matters for participation is whether the relationship yields a non-negative surplus. It also follows that the agent earns a rent from employment for any $S(e)>0$. Furthermore, for any positive surplus, the agent's compensation, and thereby the agent's utility, are increasing in his bargaining power, as in Cordero Salas (2011). Finally, under complete contractibility, if players enter into a contract, they will evidently contract on high effort as it maximizes the surplus $S(e)$ by our assumption that $H-\theta>L$.

Independent of the effort level contracted upon, social relationships affect the complete contract in three ways. Most of these results also apply to relational contracts as will be shown in the next subsection. First, note that 
the first-order condition (2) reveals that the share of surplus allocated to a player is decreasing in his altruism intensity. The reason is that a player's altruism increases the weight the other player's utility gets in determining the surplus from the relationship. A more altruistic player therefore effectively loses some bargaining power. However, second, the players' (identical) participation constraints $\left(\mathrm{PC}_{P}, \mathrm{PC}_{A}\right)$ reveal that a player is better off when he is more altruistic. The reason is that good social relationships imply an altruistic benefit of working together which increases the surplus from the contract. Hence, even though a more altruistic player earns a smaller share of surplus, he nevertheless enjoys a higher utility level. It follows directly that a player is also better off when the other player is more altruistic. Further, note that players may not enter into a contract if social relationships are too bad. This may happen when either one or both players are sufficiently spiteful. Contracts may then entail a social cost which is not compensated for by the economic surplus from the employment relationship.

Third, social relationships give rise to a compensating wage differential. Using (3), it is straightforward to derive that the agent's compensation $w^{*}(e)$ may increase or decrease in his altruism, depending on $\beta_{A}$ :

$$
\frac{\partial w^{*}(e)}{\partial \alpha}=-\left(1-\beta_{A}\right) \frac{1}{(1-\alpha)^{2}}[q(e)-e \theta-(1-\gamma) \bar{U}]+\beta_{A} \frac{\gamma}{1-\gamma} \bar{\Pi} \gtreqless 0 .
$$

In the extreme case where the agent has no bargaining power at all, his compensation decreases in $\alpha$. The intuition is that the principal extracts all the surplus from the relationship. As the agent enjoys more altruistic utility, the principal extracts this utility by decreasing the agent's pay. In the other extreme where $\beta_{A}=1$, it is the agent who extracts all rents from the relationship. Whether the agent can extract more utility from the principal if he becomes more altruistic then depends on the principal's feelings. If the principal is spiteful, she dislikes working with a more altruistic agent (simply because the agent enjoys more utility when more altruistic) and so she must be compensated; hence $w^{*}(e)$ decreases in $\alpha$ if $\beta_{A}=1$ and $\gamma<0$. On the other hand, if the principal is altruistic, she enjoys employing a more altruistic agent and so $w^{*}(e)$ increases in $\alpha$ if $\beta_{A}=1$ and $\gamma>0$. A similar but reverse intuition can be provided for the impact of the principal's altruism on the agent's compensation which is given by

$$
\frac{\partial w^{*}(e)}{\partial \gamma}=-\left(1-\beta_{A}\right) \frac{\alpha}{1-\alpha} \bar{U}+\beta_{A} \frac{1}{(1-\gamma)^{2}}[q(e)-e \theta-(1-\alpha) \bar{\Pi}] \gtreqless 0,
$$

the sign of which also depends on $\beta_{A}$, and on the sign of $\alpha$. We summarize the above results in the following Lemma. 
Lemma 1 If contracts are complete and players are not too spiteful, then players enter into a contract specifying high effort. Moreover, and independent of the effort level contracted upon:

- the agent earns compensation $w^{*}(e)$ as described by (3) which yields him a rent.

- a more altruistic player earns a smaller share of surplus, but,

- both players enjoy greater utility if either player is more altruistic.

Social relationships also imply a compensating wage differential, the sign of which depends on the agent's bargaining power. Lastly, if either one or both players are too spiteful, the participation constraint may be binding, implying that players do not contract.

\subsection{Relational Contracts}

In the previous subsection we assumed that through contracting the players can commit to create and divide the surplus as negotiated ex ante. In practice, contracts are often incomplete. This gives rise to two moral hazard problems. First, the agent may profitably deviate from the negotiated contract by choosing to shirk rather than work. If so, the agent must be given incentives (a bonus and/or threat of dismissal) that make shirking unprofitable. But then, second, the principal may deviate by withholding a promised bonus or not dismiss an agent after shirking. Hence, it must hold that any incentive that is used is credible. In the following we establish when incentives are needed, when they are credible, and what type of incentives are optimally used to prevent the agent from shirking. Finally, note that there are no profitable deviations if players decide to contract on low effort. Hence, such a contract, is self-enforcing and pays the agent compensation $w^{*}(e=0)$ as described by $(3)$.

\subsubsection{Credibility of Incentives}

A threat of dismissal is only credible when the principal is willing to fire the agent if he is caught shirking. Recall that if a contract contains a threat of dismissal and the agent is nevertheless retained after shirking, he will never believe a threat or promise in the future anymore. Hence, if the agent is retained after he is caught shirking, the agent will forever shirk. Therefore, a threat of dismissal is credible only if the principal is better off dismissing the agent than retaining the agent knowing that he will shirk, $\bar{\Pi} \geq \Pi\left(w^{*}, e=0\right)$. This condition is the reverse of the participation constraint with $e=0$ :

$$
S(e=0) \equiv L-(1-\gamma) \bar{U}-(1-\alpha) \bar{\Pi} \leq 0 .
$$


It is easy to verify that the principal's utility from a low-effort contract is increasing in the quality of social relationships as measured by $\alpha$ and $\gamma$. The intuition is that good social relationships entail an altruistic benefit of working together. Hence, the principal is not willing to fire the agent if social relationships are sufficiently good. As a result the credibility of dismissal is undermined by good social relationships. This is our first key result.

Proposition 1 Good social relationships undermine the credibility of a threat of dismissal.

The other non-contractible part of the contract is a promise to pay a bonus for high output. For the bonus to be credible, it must be in the principal's interest to pay it conditional on observing high output. Adhering implies that the principal must incur bonus costs in the present, but she retains the opportunity to implement credible incentives in the future. Focussing on the relevant case where the agent exerts high effort, the principal's lifetime utility from adhering is, by stationarity:

$$
\Pi^{A}=\frac{1}{1-\delta} \frac{1}{1-\alpha \gamma}[H-s-b+\gamma(s+b-\theta)] .
$$

Reneging on the bonus has the benefit of saving on bonus costs. However, the cost is that incentives are no longer credible in the future, implying the agent will shirk. Assuming the principal prefers to fire the agent if he shirks $(S(e=0) \leq 0)$, the principal's lifetime utility from reneging is:

$$
\Pi^{R}=\frac{1}{1-\alpha \gamma}[H-s+\gamma(s-\theta)]+\frac{\delta}{1-\delta} \bar{\Pi} .
$$

Consequently, a bonus is credible if $\Pi^{A} \geq \Pi^{R}$, which can be written as

$$
\frac{\delta}{1-\delta}[\Pi(s, b, e=1)-\bar{\Pi}]-\frac{1-\gamma}{1-\alpha \gamma} b \geq 0
$$

Similarly, if the principal prefers to retain the agent after contract breach $(S(e=0)>0)$, credibility of the bonus $\left(\mathrm{CC}_{B}^{\prime}\right)$ is guaranteed if

$$
\frac{\delta}{1-\delta}\left[\Pi(s, b, e=1)-\Pi\left(w^{*}, e=0\right)\right]-\frac{1-\gamma}{1-\alpha \gamma} b \geq 0 . \quad\left(\mathrm{CC}_{B}^{\prime}\right)
$$

The credibility constraints essentially state that paying a bonus is only credible when doing so yields sufficient rents in the future. Therefore, the credibility of a bonus increases in the principal's discount factor $\delta$. Further, it can be easily derived that the credibility of the bonus increases in the agent's 
altruism. Assuming a threat of dismissal is credible, and the agent earns total compensation equal to $w^{*}(e=1)$ as is shown to be always the case in the next subsection, one can derive:

$$
\frac{\partial \mathrm{CC}_{B}}{\partial \alpha}=\frac{\delta\left(1-\beta_{A}\right)}{1-\delta} \frac{1}{(1-\alpha)^{2}}\left[H-\theta-(1-\gamma) \bar{U}+\frac{(1-\alpha)^{2} \gamma}{1-\gamma} \bar{\Pi}\right]>0
$$

where the sign follows if participation is ensured. The intuition follows directly from Lemma 1 . If the agent is more altruistic, the value of the relationship increases. Some of this value is allocated to the principal in the contract negotiations. It follows that the principal has stronger incentives to uphold the relational contract if the agent is more altruistic. The same holds when the principal is more altruistic:

$$
\frac{\partial \mathrm{CC}_{B}}{\partial \gamma}=\frac{\delta\left(1-\beta_{A}\right)}{1-\delta} \frac{1}{(1-\gamma)^{2}}\left[H-\theta+\frac{(1-\gamma)^{2} \alpha}{1-\alpha} \bar{U}-(1-\alpha) \bar{\Pi}\right]>0 .
$$

The reason is that, as above, an increase in the principal's altruism increases the principal's rents from the relationship. In addition, a more altruistic principal experiences lower costs from paying a bonus, as she internalizes part of the benefit of the bonus to the agent. The same results hold if a threat of dismissal is not credible. ${ }^{14}$ Hence, our second key result is:

Proposition 2 Good social relationships reinforce the credibility of a promise to pay a bonus.

${ }^{14}$ Derivating $\mathrm{CC}_{B}^{\prime}$ yields:

$$
\frac{\partial \mathrm{CC}_{B}^{\prime}}{\partial \alpha}=\frac{\delta\left(1-\beta_{A}\right)}{1-\delta} \frac{1}{(1-\alpha)^{2}}(H-\theta-L)>0,
$$

and

$$
\frac{\partial \mathrm{CC}_{B}^{\prime}}{\partial \gamma}=\frac{\delta\left(1-\beta_{A}\right)}{1-\delta} \frac{1}{(1-\gamma)^{2}}(H-\theta-L)>0 .
$$

The intuition behind these comparative static results is slightly different from the one in the main text. The reason is that the principal's utility from reneging is not her outside option utility, but the utility from the low-effort contract. By Lemma 1, the principal's utility from a contract increases in both players' altruism, independent of the effort level. However, as the principal's utility rises faster with altruism under the high-effort contract compared to the low-effort contract, better social relationships make it more attractive to the principal to adhere to the bonus also if a threat of dismissal is not credible. 


\subsubsection{The Optimal Relational Contract}

Next consider the agent's incentive compatibility constraint. The agent is only willing to exert high effort if doing so yields higher expected lifetime utility than shirking does. Let's first suppose the contract contains a credible threat of dismissal. Then, keeping fixed the principal's strategy to adhere to a promise of a bonus, the agent's lifetime utility from exerting high effort is, by stationarity:

$$
U^{H}=\frac{1}{1-\delta} \frac{1}{1-\alpha \gamma}[s+b-\theta+\alpha(H-s-b)] .
$$

The agent's lifetime utility from shirking is

$$
U^{L}=\frac{1}{1-\alpha \gamma}[s+\alpha(L-s)]+\frac{\delta}{1-\delta} \bar{U} .
$$

Shirking implies that the agent does not bear any effort costs. However, the agent does not receive a bonus. In addition, the agent is fired after shirking so that his continuation utility is equal to his outside option utility. It is optimal for the agent to exert high effort if $U^{H} \geq U^{L}$ (IC), which becomes after some rewriting

$$
\frac{1-\alpha}{1-\alpha \gamma} b+\frac{\delta}{1-\delta}[U(s, b, e=1)-\bar{U}]+\frac{\alpha}{1-\alpha \gamma}(H-L) \geq \frac{1}{1-\alpha \gamma} \theta .
$$

The right-hand side denotes the agent's costs of exerting high effort. The left-hand side describes the benefits from exerting high effort which may be threefold: a bonus, a stream of future rents, and intrinsic joy of enriching the principal. Clearly, shirking can be made unprofitable by promising a bonus and/or by providing future rents in combination with a threat of dismissal.

Assuming that the agent's compensation equals $s+b=w^{*}(e=1)$ as described by (3) (which we prove always to be the case in the proof of Proposition 4), the minimum required bonus to induce high effort can be written as:

$$
b^{*}=\frac{1}{1-\alpha}\left[\theta-\alpha(H-L)-\frac{\delta \beta_{A}}{1-\delta} \frac{1-\alpha \gamma}{1-\gamma} S(e=1)\right],
$$

where $S(e=1)$ is described by $\left(\mathrm{PC}_{P}, \mathrm{PC}_{A}\right)$ with $q(e)=H$ and $e=1$. It is easy to verify that the minimum required bonus $b^{*}$ is decreasing in both players' altruism. The reason is twofold. First, a more altruistic agent experiences more altruistic utility from enriching the principal. Second, by Lemma 1 , the contract becomes more valuable to the agent if either player becomes more altruistic. Hence, provided that the contract contains a credible threat of dismissal, a lower bonus is required. 
Next suppose that a threat of dismissal is not credible and, hence, is not part of the contract. Then, the agent's effort choice does not affect his future employment status. The reason is that the principal will retain the agent in any case. The implication is that the agent's future rents can no longer be used as an incentive device. Consequently, the agent only takes the current costs and benefits of effort into account and exerts high effort if $U_{t}^{H} \geq U_{t}^{L}$ $\left(\mathrm{IC}^{\prime}\right)$. Rewriting yields that the minimum required bonus is given by:

$$
b^{* *}=\frac{1}{1-\alpha}[\theta-\alpha(H-L)] .
$$

For sufficiently strong agent's altruism, incentives are unnecessary to induce high effort. This is the case when $\alpha \geq \frac{\theta}{H-L}$. It follows directly that the optimal relational contract in this case is simply a flat wage contract without threat of dismissal. By Nash bargaining, the agent's total compensation equals $w^{*}(e=1)$ as derived above. Our next Proposition follows.

Proposition 3 Sufficiently altruistic agents $\left(\alpha \geq \frac{\theta}{H-L}\right)$, do not need incentives to exert high effort. In this case the optimal contract is a contract without incentives that results in high effort. The agent's total compensation equals $s=w^{*}(e=1)$ and so Lemma 1 also applies to this contract.

Next we derive the optimal relational contract assuming that the agent needs incentives to exert high effort. The results are given in Proposition 4 and derived and explained in detail in the subsequent proof.

Proposition 4 If the agent needs incentives to exert high effort, the optimal relational contract is described by the following Table:

\begin{tabular}{|l|l|c|}
\hline & \multicolumn{1}{|c|}{ ToD credible } & ToD not credible \\
\hline \hline \multirow{3}{*}{ Bonus credible } & a) ToD, $b \geq b^{*}, e=1$ & \\
& b) ToD, flat wage, $e=1$ & No ToD, $b \geq b^{* *}, e=1$ \\
& c) no ToD, $b \geq b^{* *}, e=1$ & \\
Bonus not credible & No contract & No incentives, $e=0$ \\
\hline
\end{tabular}

where ToD denotes threat of dismissal. Cases (b) and (c) may apply in addition to case (a) only if respectively the agent's and the principal's future rents are sufficiently large (see condition (4) and (5) below). Further, the agent's total compensation always equals $s+b=w^{*}(e)$ and so Lemma 1 also applies to these relational contracts. 
Proof. First, in the case where neither credibility constraint binds, any incentive scheme is credible and so the contract can always induce high effort. By Nash bargaining the agent's compensation is given by $s+b=w^{*}(e=1)$ which, by Lemma 1, yields the agent a rent. Given that the agent earns a rent, any bonus $b \geq b^{*}$ as described by (IC) combined with a threat of dismissal ensures high effort (Case (a)). However, there are potentially two alternatives, depending on the size of the players' rents. If the value of the agent's future rents is sufficiently high, then a threat of dismissal alone can induce high effort (Case (b)). This holds when:

$$
\frac{\delta}{1-\delta}\left[U\left(w^{*}, e=1\right)-\bar{U}\right] \geq \frac{1}{1-\alpha \gamma}[\theta-\alpha(H-L)] .
$$

If the value of the principal's future rents is sufficiently high, a bonus contract with $b \geq b^{* *}$ and no threat of dismissal can also induce high effort (Case (c)). This holds when:

$$
\frac{\delta}{1-\delta}\left[\Pi\left(w^{*}, e=1\right)-\bar{\Pi}\right] \geq \frac{1-\gamma}{(1-\alpha \gamma)(1-\alpha)}[\theta-\alpha(H-L)] .
$$

Hence, if either condition (4) or (5) holds, the players have various contract types at their disposal to induce high effort. Note that both conditions hold for the same values of $\alpha$ and $\gamma$ if $\beta_{A}=\frac{1}{2}$. However, if $\beta_{A}<\frac{1}{2}$ condition (5) binds for lower values of $\alpha$ and $\gamma$, whereas otherwise condition (4) binds for lower values of $\alpha$ and $\gamma$.

Second, consider the case where promising a bonus is credible while threatening with dismissal is not. Then, it is still possible to contract on high effort because any necessary bonus can be promised. By Nash bargaining, the agent's compensation is given by $s+b=w^{*}(e=1)$, where it must hold that $b \geq b^{* *}$ as described by (IC').

Third, if neither incentive is credible, it is not possible to induce high effort. However, if the threat of dismissal is not credible, it is by definition attractive to hire the agent even if he shirks. The agent is paid compensation resulting from Nash bargaining, $s=w^{*}(e=0)$ as described by (3). Hence, a flat wage contract without threat of dismissal is agreed to when both incentives are not credible.

The final case is that where a threat of dismissal is credible but the minimum required bonus, $b^{*}$, is not. Since the threat of dismissal is credible, it is by definition not attractive to contract on low effort. An argument similar to that of MacLeod and Malcomson (1989) proves that the principal does not find it attractive to contract on high effort either, and so no contract is agreed to at all. The argument runs as follows. 
The credibility constraint for bonus pay, given that the threat of dismissal is credible, can be rewritten as

$$
b \leq \bar{b} \equiv \delta\left(\frac{1}{1-\gamma}(H-\gamma \theta)-\frac{1-\alpha \gamma}{1-\gamma} \bar{\Pi}-s\right)
$$

where $\bar{b}$ is the maximum credible bonus. Since $\bar{b}<b^{*}$, the maximum credible bonus $\bar{b}$ is too low to satisfy the incentive compatibility constraint (IC). The only way to satisfy (IC) then is to increase the agent's rents by raising the agent's total compensation above $w^{*}(e=1)$. Even though this will result in a division of rents that is different from the division implied by Nash bargaining, it may still make the principal better off compared to the case where no contract is agreed to. However, the following argument shows that this is not the case. First note that the impact of increasing the base salary on the incentive compatibility constraint (IC) is zero if $\left(\mathrm{CC}_{B}\right)$ is met with equality:

$$
\frac{\partial \mathrm{IC}}{\partial s}=\frac{1-\alpha}{1-\alpha \gamma} \frac{\partial \bar{b}}{\partial s}+\frac{\delta}{1-\delta} \frac{1-\alpha}{1-\alpha \gamma}\left(1+\frac{\partial \bar{b}}{\partial s}\right)=0
$$

where, following $\left(\mathrm{CC}_{B}\right), \partial \bar{b} / \partial s=-\delta$. The reason is that increasing the base salary makes the contract less profitable to the principal, and hence the maximum credible bonus decreases. Therefore net incentives from raising the base salary do not increase until the maximum credible bonus equals zero. Further, if the principal can only credibly promise a bonus that is equal to zero, it must hold that she earns no rent from the contract, $\Pi(s, b=0, e=1)=\bar{\Pi}$. Moreover, the principal must still increase the base salary in order to satisfy the incentive compatibility constraint (IC). But this violates the principal's participation constraint and so she will not enter into a high-effort contract.

\subsection{Social Relationships and Contract Selection}

So far we have found that players may agree to different types of relational contracts. Players may find it optimal to include both incentive types, either one of them, or no incentives at all (see Propositions 3 and 4). Which contract type is optimal depends on the need for and credibility of incentives. This is in turn affected by the quality of social relationships as described by the pair $(\alpha, \gamma)$ (see Propositions 1 to 3 ). In this subsection we investigate what type of contract is selected for any pair $(\alpha, \gamma)$. Naturally there are many different contract mappings, depending on the exact parameterization of the model. However, there is one important qualitative distinction between the different mappings: either better social relationships always increase the value of the 


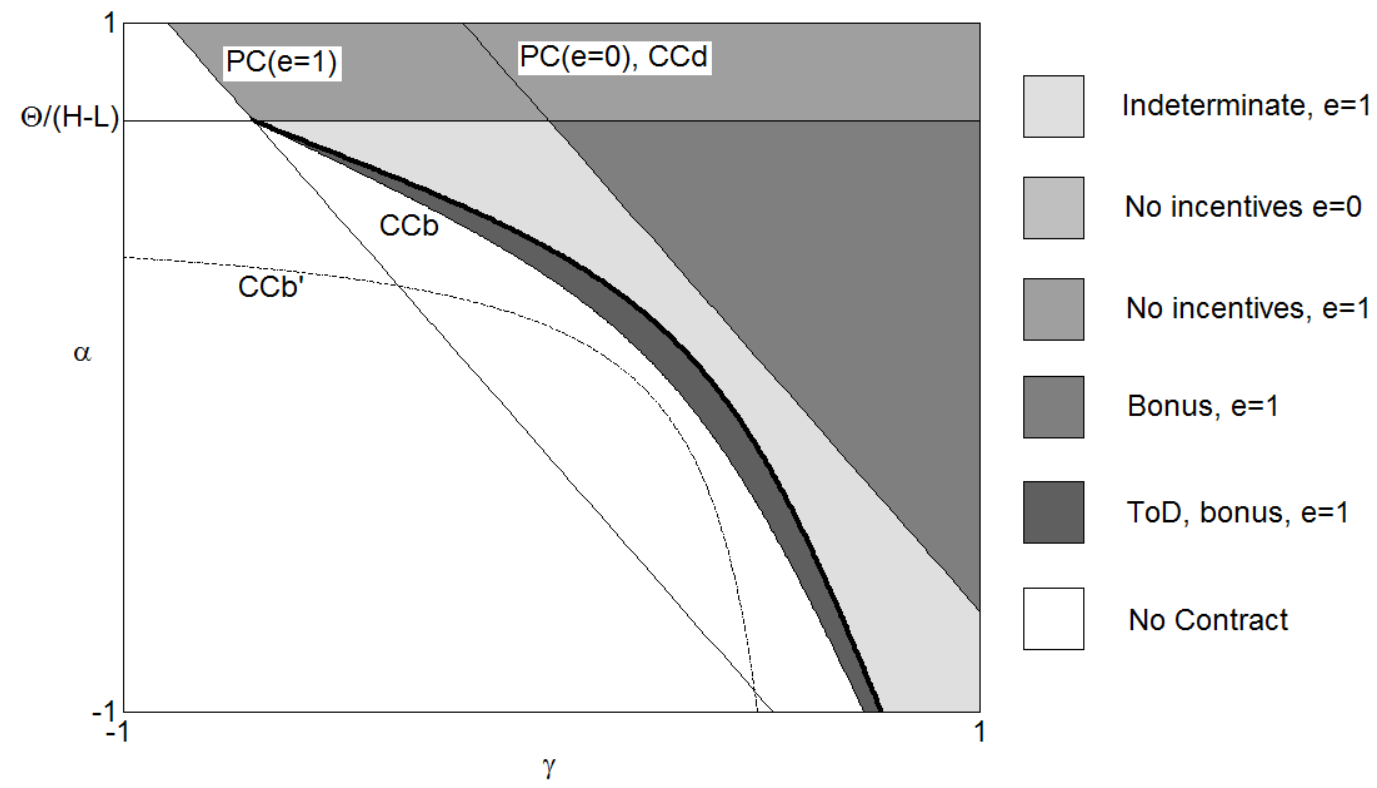

Figure 1: Contract selection as a function of social relationships. $H=2.1$, $L=1, \theta=0.7, \bar{U}=0.58, \bar{\Pi}=0.41, \beta_{A}=0.3$, and $\delta=0.75$.

relationship, or they may reduce it sometimes. We start with illustrating the first case in Figure 1, which has the following properties.

First, social relationships must be sufficiently good to satisfy the players' participation constraints. Naturally, $\operatorname{PC}(e=0)$ lies to the right of $\mathrm{PC}(e=1)$ as output is lower in the low-effort contract.

Second, high effort is only sustainable if neither player wants to deviate from a high-effort contract. Above the line $\alpha=\frac{\theta}{H-L}$ the agent has sufficient intrinsic motivation to exert high effort without incentives. Hence, above this line the optimal contract is a contract without incentives that results in high output (Proposition 3). Below the line $\alpha=\frac{\theta}{H-L}$, incentives are required to induce high effort which must be credible. $\operatorname{PC}(e=0)$ demarcates whether the principal finds it attractive to hire the agent if he shirks. Therefore to the right of $\mathrm{PC}(e=0)$ social relationships are too good to make credible use of a threat of dismissal (Proposition 1). Next, depending on the credibility of a threat of dismissal, the principal must promise the agent a bonus equal to at least $b^{*}$ or $b^{* *}$ to induce high effort. Hence, if a threat of dismissal is credible, the credibility constraint for bonus pay becomes

$$
\frac{\delta}{1-\delta}\left[\Pi\left(w^{*}, e=1\right)-\bar{\Pi}\right]-\frac{1-\gamma}{1-\alpha \gamma} b^{*} \geq 0,
$$


whereas otherwise it is

$$
\frac{\delta}{1-\delta}\left[\Pi\left(w^{*}, e=1\right)-\Pi\left(w^{*}, e=0\right)\right]-\frac{1-\gamma}{1-\alpha \gamma} b^{* *} \geq 0 . \quad\left(\mathrm{CC}_{B}^{\prime}\right)
$$

The reason that $\mathrm{CC}_{B}$ and $\mathrm{CC}_{B}^{\prime}$ are evaluated at $b^{*}$ and $b^{* *}$ is that players can always lower the bonus to this level, without changing total compensation, which would be optimal if a higher bonus is not credible. ${ }^{15}$ Hence the constraints denote when promising some bonus that induces high effort is feasible. Also note that whenever the agent needs incentives to exert high effort, $\mathrm{CC}_{B}$ lies strictly to the right of $\mathrm{PC}(e=1)$. The reason is that the principal requires a rent to be able to credibly promise a bonus.

Third, at $\mathrm{CC}_{B}$ the relationship is exactly that valuable such that the principal can promise the bonus $b^{*}$ which, in combination with a threat of dismissal, induces high effort from the agent (Proposition 4, case a). As we move to the north-east, social relationships improve, and so by Lemma 1 both players' rents increase. Therefore, at some point it holds that either the principal's or the agent's rents are equal to the agent's costs of effort. This point is determined by either equation (4) or (5) and graphically represented by the fat line. If the agent's rents equal his cost of effort, an efficiency wage contract without bonus pay induces high effort (Proposition 4, case b). Alternatively, if the principal earns sufficiently high rents, she can credibly promise a bonus that alone induces high effort (Proposition 4, case c). As it is also possible to use both tools instead of only one, several contract types are optimal beyond the fat line till $\mathrm{CC}_{D}$. The model's predictions concerning contract type are therefore indeterminate in this region. ${ }^{16}$

Fourth, anywhere beyond $\mathrm{CC}_{D}$, a threat of dismissal is not credible, but the bonus $b^{* *}$ is credible and so the optimal contract is a bonus contract that induces high effort. However, $b^{* *}$ may not always be credible beyond $\mathrm{CC}_{D}$ as we will see in Figure 2.

Figure 2 again represents the mapping from social relationships to contract type, but now for a lower value of the discount rate. This shifts the bonus credibility constraints to the right as better social ties are required to make the bonus credible. The crucial difference between Figures 1 and 2 is that there is now an intermediate region where neither incentive is credible. ${ }^{17}$ By Proposition 4, players then agree to a contract without incentives that results in low effort.

\footnotetext{
${ }^{15}$ It can also be easily checked that promising $b^{*}$ and $b^{* *}$ becomes more credible if social relationships improve.

${ }^{16}$ In Figure 1 (and Figure 2) the fat line represents equation (5). So, to the right of the fat line players can choose to only use a bonus.

${ }^{17}$ Such a region also emerges for a sufficiently high value of the agent's bargaining power $\left(\beta_{A}\right)$.
} 


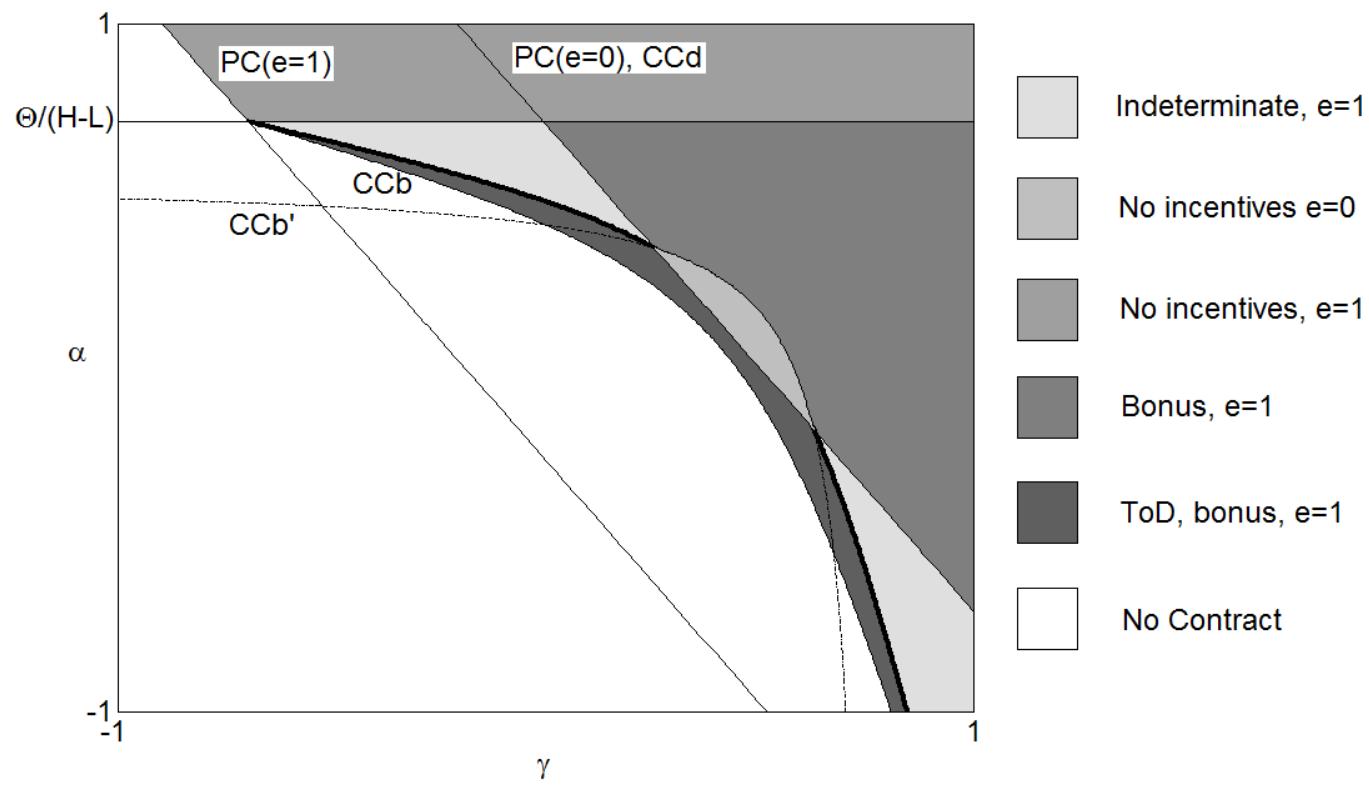

Figure 2: Contract selection as a function of social relationships. Same parameterization as above, except $\delta=0.6$.

To understand why the principal loses the possibility to promise a bonus for some pairs $(\alpha, \gamma)$ beyond $\mathrm{CC}_{D}$, consider the following. If a threat of dismissal is no longer credible, this reinforces the credibility problem concerning the bonus. The reason is two-fold. First, the principal's fallback utility from reneging is no longer her outside option utility but her utility from a loweffort contract. By definition the latter is weakly higher than the former if a threat of dismissal is not credible, and so the principal has weaker incentives to stick to her promise to pay a bonus. Second, if a threat of dismissal is not credible, the agent's rents cannot be used as an incentive device and so the minimum bonus must increase from $b^{*}$ to $b^{* *}$. This again gives the principal stronger incentives to withhold the bonus. For high values of $\delta$ it is never a problem that the bonus must increase from $b^{*}$ to $b^{* *}$ because the present value of adhering to the principal is still large enough, as in Figure 1. However, for low values of $\delta$ the principal's present value of adhering is low, and so a discrete increase in the bonus has a relatively large impact on the credibility constraint. Hence the non-credibility of a threat of dismissal may put too much strain on the promise to pay a bonus.

The optimality of a low-effort contract for intermediate levels of altruism implies two counterintuitive comparative static results. First, at the credi- 
bility constraint of a threat of dismissal, a marginal improvement in social relationships is harmful to productivity and players' utility in equilibrium. The reason is that, at $\mathrm{CC}_{D}$, a marginal improvement in social relationships renders a threat of dismissal non-credible, and hence, players lose the opportunity to credibly contract upon high effort. Second, near the credibility constraint for bonus pay $\left(\mathrm{CC}_{B}^{\prime}\right)$, better social relationships do not lead to lower bonuses as commonly found in the literature (Sliwka 2007, Shchetinin 2010, and Non 2012), but rather higher. The reason is that better social relationships enable credible use of a bonus. We summarize these results in our final Proposition.

Proposition 5 Depending on the parameterization of the model, a region may exist where players agree on a low-effort contract without incentives. Starting from this low-effort contract, it may hold that a deterioration of social relationships leads to higher productivity and higher players' utility while an improvement in social relationships can result in higher bonuses.

\section{Concluding Remarks}

The theoretical analysis in this paper yields some clear testable implications. In particular, our analysis predicts that a threat of dismissal is less likely used as an incentive device when social relationships improve. Conversely, social relationships facilitate subjective bonus pay arrangements and, at some point, make incentives redundant. Laboratory experiments are potentially very effective in testing contract selection as a function of social relationships. In this type of experimenting, the researcher has the freedom to fine-tune the profitability of the various types of contracts, which is hard outside the lab. Moreover, in contrast to the field, one can easily observe when players decide not to enter into a contract. A bottleneck may be to bring feelings of altruism and, particularly, feelings of spite into the lab. This difficulty may be resolved by recruiting subject pools in which social relationships are already present. One could think of members of (non-)rivalrous sports clubs or student associations. Using field data, one can test whether there is a relationship between contract types and the quality of social relationships between manager and employee.

Theoretically, there are potential avenues for future research as well. First, it would be interesting to endogenize the emergence of vertical social relationships in the workplace. Dur (2009), Englmaier and Leider (2012), and Non (2012) have taken some steps in this direction in static frameworks. Building on Rabin (1993), Englmaier and Leider (2012) assume that an employee cares more about his manager's payoff when the manager leaves a rent 
to him. If such reciprocal motivations are sufficiently strong, it is optimal for the manager to leave a rent and provide weak monetary incentives, thus reducing the risk premium that needs to be paid to the employee. In Dur (2009) and Non (2012), manager's altruism is not observed and employees are conditionally altruistic, as in Levine (1998). Managers therefore have an incentive to credibly signal their altruism through gift-giving. The most efficient way to do so is to provide benefits that are otherwise underprovided (e.g., attention, as in Dur 2009), or to mute incentives and increase the base salary, as in Non (2012).

Second, it could be interesting to study how an opportunity to use objective performance measures at some cost affects optimal contract selection. Objective performance measures are likely used when subjective performance contracts fail; that is, when social relationships are mediocre. However, as in Baker et al. (1994), there may be further implications, because the opportunity to use costly objective performance measures may affect the principal's incentives to renege on subjective performance pay.

Lastly, the model can be extended to include multiple principals and agents and matching. Yang (2008) has recently developed such a general equilibrium model, abstracting from social relationships. 


\section{References}

[1] Agell, Jonas (2004), "Why Are Small Firms Different? Managers' Views." Scandinavian Journal of Economics, 106(3): 437-452.

[2] Andreoni, James and John Miller (2002), "Giving according to GARP: An Experimental Test of the Consistency of Preferences for Altruism." Econometrica, 70(2): 737-753.

[3] Andreoni, James, William T. Harbaugh and Lise Vesterlund (2008), "Altruism in Experiments." In Steven N. Durlauf and Lawrence E. Blume (Eds.), The New Palgrave Dictionary of Economics Online, Palgrave Macmillan.

[4] Baker, George, Robert Gibbons and Kevin J. Murphy (1994), "Subjective Performance Measures in Optimal Incentive Contracts." Quarterly Journal of Economics, 109(4): 1125-1156.

[5] Barro, Robert J. (1974), "Are Government Bonds Net Wealth?" Journal of Political Economy, 82(6): 1095-1117.

[6] Bartling, Björn (2011), "Relative Performance or Team Evaluation? Optimal Contracts for Other-Regarding Agents." Journal of Economic Behavior and Organization, 79(3): 183-193.

[7] Bartling, Björn and Ferdinand Von Siemens (2010a), "The Intensity of Incentives in Firms and Markets: Moral Hazard with Envious Agents." Labour Economics, 17(2): 598-607.

[8] Bartling, Björn and Ferdinand Von Siemens (2010b), "Equal Sharing Rules in Partnerships." Journal of Institutional and Theoretical Economics, 166(2): 299-320.

[9] Becker, Gary S. (1974), "A Theory of Social Interactions." Journal of Political Economy, 82(6): 1063-1093.

[10] Beckman, Steven R., John P. Formby, W. James Smith and Buhong Zheng (2002), "Envy, Malice and Pareto Efficiency: An Experimental Examination." Social Choice and Welfare, 19(2): 349-367.

[11] Bergstrom, Theodore C. (1999), "Systems of Benevolent Utility Functions." Journal of Public Economic Theory, 1(1): 71-100. 
[12] Berman, Evan M., Jonathan P. West and Maurice N. Richter (2002), "Workplace Relations: Friendship Patterns and Consequences (According to Managers)." Public Administration Review, 62(2): 217-230.

[13] Bernheim, B. Douglas and Oded Stark (1988), "Altruism Within the Family Reconsidered." American Economic Review, 78(5): 1034-1045.

[14] Brown, Martin, Armin Falk and Ernst Fehr (2004), "Relational Contracts and the Nature of Market Interactions." Econometrica, 72(3): 747-780.

[15] Brown, Martin, Armin Falk and Ernst Fehr (2008), "Competition and Relational Contracts: The Role of Unemployment as a Disciplinary Device." Journal of the European Economic Association, forthcoming.

[16] Bull, Clive (1987), "The Existence of Self-Enforcing Implicit Contracts." Quarterly Journal of Economics, 102(1): 147-159.

[17] Campbell, Carl. M. and Kunal S. Kamlani (1997), "The Reasons for Wage Rigidity: Evidence From a Survey of Firms." Quarterly Journal of Economics, 112(3): 759-789.

[18] Carmicheal, Lorne (1983a), "Firm-Specific Human Capital and Promotion Ladders." Bell Journal of Economics, 14(1): 251-258.

[19] Carmicheal, Lorne (1983b), "The Agent-Agents Problem: Payment by Relative Output." Journal of Labor Economics 1(1): 50-65.

[20] Charness, Gary and Ernan Haruvy (2002), "Altruism, Equity and Reciprocity in a Gift-Exchange Experiment: An Encompassing Approach." Games and Economic Behavior, 40(2): 203-231.

[21] Cordero Salas, Paula (2011), "The Role of Bargaining Power on Relational Contracts." SSRN Working Paper.

[22] Cordero Salas, Paula and Brian Roe (2012), "The Role of Cooperation and Reciprocity in Structuring Carbon Sequestration Contracts in Developing Countries." American Journal of Agricultural Economics, 94(2): 411-418.

[23] Cox, James C. (2004), "How to Identify Trust and Reciprocity." Games and Economic Behavior, 46(2): 260-281. 
[24] Cox, James C., Daniel Friedman and Steven Gjerstad (2007), "A Tractable Model of Reciprocity and Fairness." Games and Economic Behavior, 59(1): 17-45.

[25] Dur, Robert and Amihai Glazer (2008), "Optimal Contracts When a Worker Envies His Boss." Journal of Law, Economics, and Organization, 24(1): 120-137.

[26] Dur, Robert (2009), "Gift Exchange in the Workplace: Money or Attention?" Journal of the European Economic Association, 7(2-3), 550-560.

[27] Dur, Robert and Joeri Sol (2010), "Social Interaction, Co-Worker Altruism, and Incentives." Games and Economic Behavior, 69(2): 293-301.

[28] Ederer, Florian and Andrea Patacconi (2010), "Interpersonal Comparison, Status and Ambition in Organizations." Journal of Economic Behavior and Organization, 75(2): 348-363.

[29] Englmaier, Florian and Stephen Leider (2012), "Contractual and Organizational Structure with Reciprocal Agents." American Economic Journal: Microeconomics, 4(2): 146-83.

[30] Englmaier, Florian and Achim Wambach (2010), "Optimal Incentive Contracts under Inequity Aversion." Games and Economic Behavior, 69(2): 312-328.

[31] Falk, Armin, Ernst Fehr and Urs Fischbacher (2005), "Driving Forces Behind Informal Sanctions." Econometrica, 73(6): 2017-2030.

[32] Fehr, Ernst, Alexander Klein and Klaus Schmidt (2007), "Fairness and Contractual Design." Econometrica 75(1): 121-154.

[33] Fehr, Ernst, Daniela Rützler and Matthias Sutter (2011), "The Development of Egalitarianism, Altruism, Spite and Parochialism in Childhood and Adolescence." IZA Discussion Paper No. 5530.

[34] Fehr, Ernst and Klaus Schmidt (2000), "Fairness, Incentives, and Contractual Choices." European Economic Review, 44(4-6): 1057-1068.

[35] Gerstner, Charlotte R. and David V. Day (1997), "Meta-Analytic Review of Leader-Member Exchange Theory: Correlates and Construct Issues." Journal of Applied Psychology, 82(6): 827-844.

[36] Gibbons, Robert (1998), "Incentives in Organizations." Journal of Economic Perspectives, 12(4): 115-132. 
[37] Gibbs, Micheal (2012), "Design and Implementation of Pay for Performance." Oxford Handbook in Managerial Economics, forthcoming.

[38] Gibbs, Michael, Kenneth A. Merchant, Wim A. Van der Stede, and Mark E. Vargus (2004), "Determinants and Effects of Subjectivity in Incentives." The Accounting Review, 79(2): 409-436.

[39] Giebe, Thomas and Oliver Gürtler (2012), "Optimal Contracts for Lenient Supervisors." Journal of Economic Behaviour and Organization, 81(2): 403-420.

[40] Gneezy, Uri, Werner Güth, and Frank Verboven (2000), "Presents or Investments? An Experimental Analysis." Journal of Economic Psychology, 21(5): 481-493..

[41] Grund, Christian and Dirk Sliwka (2005), "Envy and Compassion in Tournaments." Journal of Economics and Management Strategy, 14(1): 187-207.

[42] Itoh, Hideshi (2004), "Moral Hazard and Other-Regarding Preferences." Japanese Economic Review, 55(1): 18-45.

[43] Kahneman, Daniel, Alan B. Krueger, David A. Schkade, Norbert Schwarz, and Arthur A. Stone (2004), "A Survey Method for Characterizing Daily Life Experience: The Day Reconstruction Method." Science, 306(5702): 1776-1780.

[44] Kragl, Jenny and Julia Schmid (2009), "The Impact of Envy on Relational Incentive Contracts." Journal of Economic Behavior and Organization, 72(2): 766-779.

[45] Kragl, Jenny (2009), "Group vs. Individual Performance Pay in Relational Employment Contracts when Workers Are Envious." European Business School Research Paper No. 09-09.

[46] Kragl, Jenny (2011), "Individual vs. Relative Performance Pay with Envious Workers and Non-verifiable Performance." European Business School Research Paper No. 11-04.

[47] Lee, Samuel and Petra Persson (2011), "Authority versus Loyalty: Social Incentives and Modes of Governance." NYU Working Paper, No. FIN$10-001$. 
[48] Leider, Stephen, Markus M. Möbius, Tanya Rosenblat, and Quoc-Anh Do (2009), "Directed Altruism and Enforced Reciprocity in Social Networks." Quarterly Journal of Economics, 124(4): 1815-1851.

[49] Levin, Jonathan (2003), "Relational Incentive Contracts." American Economic Review, 97(3): 835-857.

[50] Levine, David K. (1998), "Modeling Altruism and Spitefulness in Experiments." Review of Economic Dynamics, 1(3): 593-622.

[51] MacLeod, W. Bentley and James M. Malcomson (1989), "Implicit Contarcts, Incentive Compatibility, and Involuntary Unemployment." Econometrica, 57(2): 447-480.

[52] MacLeod, W. Bentley and James M. Malcomson (1998), "Motivation and Markets." American Economic Review, 88(3): 388-411.

[53] MacLeod, W. Bentley and Daniel Parent, (2000), "Job Characteristics and the Form of Compensation." In Polachek, Solomon and Konstantinos Tatsiramos (Eds.), Research in Labor Economics, Emerald Group Publishing Limited.

[54] Malcomson, James M. (1984), "Work Incentives, Hierarchy, and Internal Labor Markets." Journal of Political Economy, 92(3): 486-507.

[55] Malcomson, James M. (1986), "Rank-Order Contracts for a Principal with Many Agents." Review of Economic Studies, 53(5): 807-817.

[56] Millward, Neil, Mark Stevens, David Smart, and W.R. Hawes (1992), Workplace Industrial Relations in Transition: The ED/ESRC/PSI/ACAS Surveys. Aldershot: Dartmouth.

[57] Moerbeek, Hester H.S. and Ariana Need (2003), "Enemies at Work: Can They Hinder Your Career?" Social Networks, 25(1): 67-82.

[58] Neilson, William S. and Jill Stowe (2010). "Piece-Rate Contracts for Other-Regarding Workers." Economic Inquiry, 48(3): 575-586.

[59] Non, Arjan (2012), "Gift-Exchange, Incentives, and Heterogeneous Workers." Games and Economic Behavior, 75(1): 319-336.

[60] Prendergast, Canice (1999), "The Provision of Incentives in Firms." Journal of Economic Literature, 37(1): 7-63. 
[61] Prendergast, Canice (2002), "Uncertainty and Incentives." Journal of Labor Economics, 20(2): 115-137.

[62] Prendergast, Canice and Robert H. Topel (1996), "Favoritism in Organizations." Journal of Political Economy, 104(5): 958-978.

[63] Raff, Daniel M.G., and Lawrence H. Summers (1987), "Did Henry Ford Pay Efficiency Wages?" Journal of Labor Economics, 5(4): S57-S86.

[64] Rabin, Matthew (1993), "Incorporating Fairness into Game Theory and Economics." American Economic Review, 83(5): 1281-1302.

[65] Rey-Biel, Pedro (2008). "Inequity Aversion and Team Incentives." Scandinavian Journal of Economics, 108(2), 297-320.

[66] Rhoades, Linda and Robert Eisenberger (2002), "Perceived Organizational Support: A Review of the Literature." Journal of Applied Psychology, 87(4): 698-714.

[67] Rotemberg, Julio J. (1994), "Human Relations in the Workplace." Journal of Political Economy, 102(4): 684-717.

[68] Shapiro, Carl and Joseph E. Stiglitz (1984), "Equilibrium Unemployment as a Worker Discipline Device." American Economic Review, 74(3): 433-444.

[69] Shchetinin, Oleg (2010), "Altruism and Career Concerns." Gothenborg University, Working Papers in Economics 427.

[70] Sliwka, Dirk (2007), "Trust as a Signal of a Social Norm and the Hidden Costs of Incentive Schemes." American Economic Review, 97(3): 9991012.

[71] Von Siemens, Ferdinand (2010), "Social Preferences, Sorting and Competition." Scandinavian Journal of Economics, forthcoming.

[72] Von Siemens, Ferdinand (2011), "Heterogeneous Social Preferences, Screening and Employment Contracts." Oxford Economic Papers, 63(3): 499-522.

[73] Wayne, Sandy J., Lynn M. Shore and Robert C. Liden (1997), "Perceived Organizational Support and Leader-Member Exchange: A Social Exchange Perspective." Academy of Management Journal, 40(1): 82-111. 
[74] Yang, Huanxing (2008), "Efficiency Wages and Subjective Performance Pay." Economic Inquiry, 46(2): 179-196. 